\section{LA MIRADA SOCIAL EN LA PRENSA: CONCEPCIÓN ARENAL}

\author{
María del Carmen Simón Palmer \\ Consejo Superior de Investigaciones Científicas \\ carmen.simon@cchs.csic.es
}

Cómo citar este artículo/Citation: Simón Palmer, M. C. (2014). "La mirada social en la prensa: Concepción Arenal". Arbor, 190 (767): a142. doi: http://dx.doi.org/10.3989/ arbor.2014.767n3013

Recibido: 3 julio 2013. Aceptado: 6 abril 2014.

RESUMEN: Concepción Arenal dejó en La Voz de la Caridad, sus opiniones sobre una serie de problemas sociales que, aún hoy, siguen de plena actualidad aunque no han merecido tanta atención como los referentes a la mujer, los presos o la pobreza.

PALABRAS CLAVE: Concepción Arenal; La Voz de la Caridad; trabajos peligrosos; libertad de cultos; desahucios; alcoholismo; sueldo de obreros; Cajas de Ahorros; fiesta de toros.

Es muy difícil aportar alguna novedad sobre la obra de Concepción Arenal, una autora con una personalidad singular que rompió con los roles asignados a su sexo y abordó, por escrito y sin concesiones, temas conflictivos como la situación de los presos, de los pobres o de la mujer.

En el plano ideológico no se adscribió a ninguna escuela pero estuvo cercana a un liberalismo cristiano, liberalismo que dejó más patente a medida que la situación política se lo permitió. Destaca asimismo el hermetismo que guarda de su vida privada, sin molestarse en desmentir la idea de una austeridad impuesta

\section{THE SOCIAL LOOK IN THE PRESS: CONCEPCIÓN ARENAL}

Copyright: (C) 2014 CSIC. Este es un artículo de acceso abierto distribuido bajo los términos de la licencia Creative Commons Attribution-Non Commercial (by-nc) Spain 3.0.

ABSTRACT: In La Voz de la Caridad Concepción Arenal set out her views on a series of social problems that remain current even today, although though they have not received as much attention as those relating to women, prisoners, or poverty.

KEYWORDS: Concepción Arenal; La Voz de la Caridad; dangerous jobs; freedom of religion; evictions; alcoholism; labour wages; savings banks; bullfights.

por las circunstancias económicas, que acompañó con la negativa a dejarse fotografiar, de modo que solo quedó su imagen vestida de negro, sin ningún adorno salvo el broche que menciona en su testamento de 1872 , donde se define como propietaria y descubre una serie de propiedades de las que nunca hizo publicidad. Este secretismo no hubiera sido posible de no contar con personas que la mantuvieron alejada de las intrigas. Fue la primera su íntima amiga Juana Vega, condesa de Espoz y Mina, además de algunas figuras destacadas de la política como Olózaga y del mundo intelectual como Fernando de Castro, que incluso se acordarían de ella en sus respectivos testamentos. Su 
hijo, Fernando, que en los últimos años hace de agente literario, concierta sus colaboraciones con Lázaro Galdiano en La España Moderna y se asegura antes las intenciones del editor con sus amigos krausistas. Sin embargo, a pesar de su independencia no pudo evitar en más de una ocasión ser víctima de las rencillas de la política y la destitución de sus cargos.

En los inicios de su carrera muestra su afición a la literatura con algunas composiciones poéticas, tres obras de teatro, una novela y un libro de fábulas en verso.

Sus colaboraciones en la prensa no van a ser muy frecuentes.

En 1855, junto a su esposo, García Carrasco, comienza a colaborar en La Iberia, periódico liberal fundado por Pedro Calvo Asensio, y el 28 de julio de 1855 inicia el primero de una serie de siete artículos que llevan como título "Watt, su vida y sus inventos". Ya demuestra unos intereses diferentes de los propios de su sexo entonces, al fijarse en la figura de este ingeniero escocés cuya obra supuso un gran avance en la revolución industrial, con la mejora de la máquina de vapor y la creación de la unidad de potencia que lleva su nombre.

Tras el fallecimiento de su esposo, la primera colaboración que encontramos es en El Cristianismo, de Madrid, ya interesada en la Filantropía y la Caridad (1862). Dos años más tarde es nombrada, el 4 de abril de 1864 , Visitadora de Prisiones de Mujeres y se traslada a La Coruña, donde conocerá personalmente a la condesa de Espoz y Mina, que se convertirá en una de sus mejores amigas y colaboradoras. En 1865 publica Cartas a los delincuentes (1865) donde trata de la necesidad de reformar el Código Penal, lo que provoca su cese inmediato.

En El álbum de las familias su firma aparece en 1866 junto a la de autoras como la espiritista Amalia Domingo Soler, Ventura Ruiz Aguilera, Hartzenbusch, Ángela Grassi, etc. Reproduce unas veces fragmentos de sus obras, como el titulado "El dolor", extraído del Manual del visitador del pobre: "Sin lucha, sin contrariedad, sin abnegación, sin prueba, sin sacrificio, sin dolor, en fin, no es posible moralidad ni virtud" (Álbum de las Familias, 18-VI-1866); otras, breves "Pensamientos" sobre lo circunstancial que es la pobreza y la necesidad de hacer el bien quien no la sufre. (Álbum de las Familias, 13 y 27-VII-1866)

Tras la Revolución del 68, el gobierno provisional presidido por Serrano la nombra Inspectora de Casas de Corrección de Mujeres, cargo que desempeña hasta 1873 , aunque mantiene una postura crítica ante las medidas políticas que manifiesta en su Examen de las bases aprobadas por las Cortes para la reforma de las prisiones (1869).

Su vena patriótica le lleva a escribir en diciembre de 1868 un poema en honor al marino, héroe de la bataIla del Callao, que había fallecido poco antes: A Méndez Núñez ["Cuando surcas el piélago profundo..."] (EI Moro Muza, 14-II-1869)

Cuando ya ha iniciado la publicación de su gran revista altruista La Voz de la Caridad, reproduce alguno de sus poemas de los "Anales de la virtud", en La Ilustración de Madrid (1871); en El Abolicionista sus ideas sobre la esclavitud (1873-1875); en la Revista de España su "Juicio crítico sobre las obras del Padre Feijoo" (1875); en Los Niños, emplea la poesía para hablarles del Padrenuestro, la Salve o la Semana Santa (18721876). De la misma manera que sorprende encontrar la firma de Rosario de Acuña entre los figurines de EI Correo de la Moda, sucede con Concepción Arenal, que en cinco artículos sucesivos hablará a las lectoras de esta publicación sobre los perjuicios del servicio doméstico, los asilos y las sociedades de beneficencia (El Correo de la Moda, 1878-1882). En los últimos diez años de su vida sus preferencias se inclinan por el Boletín de la Institución Libre de Enseñanza, donde tiene grandes amigos y expone sus ideas acerca de la miseria y queda patente su preocupación por la dignidad y libertad de la mujer y la necesidad de instruirla igual que al obrero y al preso.

Su firma aparece también en La Ilustración gallega y asturiana (1880-1881), El Día (1881) y por último en La España Moderna, para la que Lázaro Galdiano consigue su participación, ya en 1890 . Hasta poco antes de fallecer continua trabajando y enviando sus composiciones simultáneamente a varias revistas, como la titulada "Desigualdad excesiva" en Las Dominicales del Librepensamiento (1892). El mismo mes en que muere aparece en La Ilustración Española y Americana su poema "El proyectista" ["Si no ha mentido o se engaña..."] sobre aquellos que no escuchan a los hombres sabios que proponen medidas para mejorar la sociedad (La Ilustración Española y Americana, 22II-1893).

Siempre firmó sus escritos aunque en algunas publicaciones tuvo, en ocasiones, que advertir de su no adhesión a la doctrina de sus redactores. Esto sucede, por ejemplo, cuando tras admitir el gobierno en 1868 la libertad de asociación, y crearse en 1872 Las Hijas 
del Sol, revista órgano de la asociación masónica del mismo nombre, al frente de la cual está la Baronesa de Wilson, incluyen su nombre como colaboradora. Indignada, va a escudarse en su baja por enfermedad tras el fallecimiento de la Condesa de Mina, para negar cualquier vinculación.

En 1873 se crea la rama femenina de la Asociación Abolicionista a la que pertenecen ilustres masones y en la que inicialmente figura, pero pronto se separa. También participa como secretaria de la Cruz Roja y tiene que enfrentarse de nuevo a la acusación de pertenecer a una asociación masónica por parte de $E I$ Consultor de los Párrocos.

Fuera de sus libros, puso la atención en la publicación de La Voz de la Caridad, subtitulada Revista quincenal de Beneficencia y Establecimientos Penales, fundada en 1870 y en la que, como en todos aquellos colectivos en que colabora, nunca figura como responsable, aunque de hecho lo fuera en gran medida. ${ }^{1}$ En 1873 con motivo de la Exposición de Viena se les pide una explicación histórica de sus orígenes, explica entonces que unas pocas personas concibieron la idea de fundar un periódico destinado a tratar exclusivamente las cuestiones de los pobres y de los presos y penados, porque pensaban que debían estar representados en la prensa, trabajando en ello gratuitamente para poder aplicar el producto de la subscripción al socorro de familias necesitadas ( $L a$ Voz de la Caridad, 1-I-1873). Dos personas aportaron el capital inicial, la condesa de Espoz y Mina y Fernando de Castro que luego siguieron contribuyendo hasta que el periódico pudo sostenerse por sí mismo.

En la "protesta" inicial los redactores dejan claro que, si bien tienen sus propias ideas políticas, estas quedan fuera de la revista, aunque se temen que los lectores tratarán de formar un juicio político de ella (La Voz de la Caridad, 15-III-1870).

No se limitan a exponer las cuestiones relativas a los pobres y encarcelados sino que pronto añaden hechos concretos: abren una suscripción para los heridos en la guerra franco- prusiana, establecen en España la institución francesa del Patronato de los Diez, que en París se llama Obra de las Familias y un Taller de Caridad, donde semanalmente se reúne un grupo de señoras y cosen ropa para los pobres, que entregaban los lectores en la redacción de la revista. Arenal propone que, además de las noches de moda para acudir al teatro haya noche de caridad para vestir al desnudo (La Voz de la Caridad, 1-III-1872) y lo cierto es que puso a hacer hilas a las aristócratas en el pala- cio de la Duquesa de Medinaceli, los años en que fue secretaria de la Cruz Roja.

Arenal no mantuvo ningún contacto directo con Isabel II, aunque la condesa de Mina intercedió por carta ante su antigua pupila para que colaborara en sus obras benéficas: Sí va a obsequiar, en cambio, el primer tomo de la revista a la Reina María Victoria, esposa de Amadeo de Saboya, algo que no sorprende al ser su amigo Salustiano de Olózaga, embajador en Francia del monarca. La nueva revista sería apoyada por publicaciones de ideología liberal, con responsables que en ese tiempo ocupaban algunos altos puestos en la Universidad.

Colaboran en ella, entre otros, Josefa Ugarte Barrientos, Fermín Caballero. Carlos Mạ Perier, Emilia Mijares del Real, Leopolda Gassó y Vidal, Joaquina García Balmaseda, Micaela de Silva, etc.

Poco conocida es la mutua admiración entre Concepción Arenal y Gertrudis Gómez de Avellaneda y de esta con Guerola. El año 1871, publican una carta suya pidiendo ayuda para un convento de cuarenta monjas desvalidas, que han sufrido un incendio y una inundación (La Voz de la Caridad, 15-III-1871). Dos años después, se da noticia de un nuevo legado de la señora Avellaneda, son siete onzas de oro para siete pobres ciegos o baldados, cantidad de la que Hacienda se quedará con el diez por ciento ( $L a$ Voz de la Caridad, 1-III-1873).

Pero sin duda su alter ego fue hasta su fallecimiento Juana Vega, condesa de Espoz y Mina, aya en su juventud de Isabel II y escritora de las memorias de su esposo. Juntas desarrollaron una gran labor benéfica y Arenal estuvo a su lado cuando cayó enferma en una casa de huéspedes, de viaje, por lo que dejó un tiempo la revista para atenderla porque la condesa no tenía parientes cercanos, Al regresar agradece a todos los que se han interesado por ella ( $L a$ Voz de la Caridad, 1-XII-1871), y cuando fallece se le dedica gran parte de un número con la portada orlada de luto. Pilar Matamoros de Tornos, amiga de ambas, resalta su vida ejemplar y consagrada al alivio y consuelo de los sufrimientos, Emilia Mijares le dedica un poema y el conde de Ripalda da el pésame a Arenal ( $L a$ Voz de la Caridad, 1-VII-1872). Quince días después, Fernando de Castro escribe "A los que lloran a la Condesa de Mina" y el 15 de agosto se habla del entierro y de su testamento. Sabemos que Concepción Arenal cae enferma y deja de escribir unos meses, después de los que su colaboración continúa sin interrupción hasta el año 1875 , cuando la mujer de su hijo sufre una enfer- 
medad irreversible de la que muere ese año. Entonces se trasladará de Madrid a Gijón, donde Fernando obtuvo plaza de ingeniero en el puerto.

En 1874, al fallecer Fernando de Castro, Arenal, que pierde un gran amigo, recuerda cómo cuatro años fue una de las dos personas que aportaron fondos para publicar La Voz de la Caridad y pertenecía a dos Decenas, un organismo creado por ella por el que diez personas se hacían cargo de una familia, además de ofrecer frecuentes limosnas para los pobres ( La Voz de la Caridad, 15-V-1874).

Se supone que las relaciones de Arenal con Antonio Guerola, el otro factotum de la revista, fueron cordiales puesto que ambos estuvieron al principio al frente de la publicación y él la sustituyó en los periodos de baja escribiendo más artículos y buscando otros autores para llenar los números. Por eso extraña su comentario sobre la obra francesa Le Visiteur du pauvre, de Mr. de Gerande, premiada en 1820 por la Academia Francesa, que era poco conocida en España y no había sido traducida. Establece una comparación con la de Concepción Arenal, El visitador del pobre, publicada bastantes años antes que su artículo, en 1863 (31-I-1871) Cuando Guerola entre en política dejará el cargo de director y años después, al intentar volver, Arenal le aconsejará no hacerlo.

En 1871 es nombrada secretaria general de la Cruz Roja de Madrid, y desde entonces La Voz de la Caridad dará cuenta de todas sus iniciativas durante las guerras carlistas. Su defensa de este organismo, que actúa bajo el lema: "Los enemigos heridos son hermanos", le supone un ataque en El Consultor de los párrocos, escrito por un sacerdote. Cuando se dispone a protestar se entera de que la Asociación ha encargado su defensa a D. Antonio Balbín y Unquera ( La Voz de la Caridad, 1-XII-1873).

Arenal inicia su colaboración con "La ley y la Beneficencia" ante su posible reforma, ya que la existente la centralizaba, y años más tarde recogerá sus artículos sobre Beneficencia y Prisiones en cinco volúmenes de sus Obras Completas (Arenal, 1900-1901, pp. 18-21).

Da la impresión de que la vocación literaria de Arenal era la poesía y eso explica la cantidad de composiciones en verso que, con un tono siempre moralista, compone para ilustrar en su revista distintos tipos de desgracias o heroicidades en esos primeros años, casi todos bajo el epígrafe Anales de la virtud, donde deja claro en qué consiste para ella la virtud: la "Resignación" como consuelo, la "Dignidad. Amor al trabajo" [iPobre Jaime! ¡Cuán alegre...], que narra la historia de un joven inválido que decide estudiar; "La limosna del pobre" [En una humilde vivienda...], sobre la limosna que da una desvalida para los pobres.

También utiliza el verso para ensalzar actos heroicos: en la "Precocidad para el bien" relata la salvación de un niño por otro que ha sido premiado por la Sociedad Económica de Barcelona, el caso de un empleado de la Bolsa que había devuelto un saco lleno de valores a su propietario: "Probidad heróica": [Será la gloria y la fama...] (La Voz de la Caridad, 15-VIII1870), o el larguísimo titulado "Abnegacion heróica. Francisco Sola" [No es en humilde romance,...], sobre este hombre que salva a los tripulantes de un barco y al que acaba aconsejándole que se cuide "que no te queremos mártir / los que te hemos visto santo" ( $L a$ Voz de la Caridad, 1-I-1873). Ante cada desgracia en distintas provincias: inundaciones, epidemias, Arenal escribe un poema solicitando ayuda.

Además de los asuntos que menciona el subtítulo de la revista y que han sido objeto de estudios rigurosos, hay otros colaterales intercalados en los que vamos a detenernos por su actualidad dentro de una inmensa obra, muy estudiada.

\section{TRABAJOS INSALUBRES Y PELIGROSOS}

Bajo este epígrafe general nos deja sus opiniones sobre profesiones que hoy se han transformado y por eso resulta interesante su descripción. Por ejemplo, el cartero vestía entonces con levita abierta con botón dorado, vuelta encarnada en la manga, gorra con vivo y visera, llevaba una bolsa de cuero y un paquete de papeles, andaba deprisa y caía enfermo a menudo por el frío que pasaba hasta que acudía el interesado a recoger su carta: aún no existían los buzones en las casas. La única compensación era una propina en navidad (La Voz de la Caridad, 15-X-1873).

Otro trabajo que considera, en este caso peligroso, es el del marinero ( $L a$ Voz de la Caridad, 1-XI-1873) porque al estar muchos meses inactivo suele caer en algunos vicios.

El servicio doméstico es otra de las profesiones que considera censurables y que recomienda suprimir en aquellas casas que no sean ricas. Comprende que llevará tiempo el conseguir un cambio de hábitos en España porque, aunque las aspiraciones a la independencia y a la igualdad son inevitables, el que las señoras acepten que pueden hacer muchas tareas domésticas, sin dejar de serlo, no es sencillo. Está convencida de lo difícil que es que la criada y el criado no sean un elemento de inmoralidad en el hogar domés- 
tico, además de la ruina que suponen para muchos hogares y está convencida de que la solución vendrá de los adelantos científicos e industriales aplicados al hogar (La Voz de la Caridad, 1-III-1878).

Otro trabajo peligroso, entonces y ahora, es el de los obreros y especialmente el del albañil, víctima por los frecuentes accidentes que padece y que podrían evitarse fácilmente, por ejemplo, con poner barandillas y redes en los andamios como hacen en el extranjero. Propone la creación de una "Asociación protectora de la salud y de la vida de los obreros", que se ocupe de que sean indemnizados debidamente por los perjuicios causados, tras discutir si es el Estado el que debe atender al inválido del trabajo o corresponde al patrón (La Voz de la Caridad,15-IV-1876 y 1-V-1876).

\section{LA LIBERTAD DE CULTOS}

No oculta Arenal nunca sus creencias religiosas de modo que cuando salta la polémica de la libertad de cultos en 1871, ya bajo el reinado de Amadeo I, ella va a defender la necesidad del regreso de las Hermanas de la Caridad a las casas de beneficencia porque cree que un establecimiento de este tipo "necesita religión". Ante el argumento de que el Estado no la tiene, defiende que la libertad consiste en no imponerla, no en suprimirla, porque nunca es una negación, ( $L a$ Voz de la Caridad, 15-IX-1871). Esas Hermanas junto a otras órdenes religiosas van a encargarse de una función, que por desgracia ha vuelto a ser importante en nuestros días, como es el reparto de comida, los hoy llamados comedores sociales y entonces Comedores de caridad, en una sociedad con multitud de mendigos tan bien reflejados en la literatura por Galdós o Baroja. La misma reina María Victoria costea entonces dos mil raciones diarias de comida pero el sistema de distribución de los bonos no se hace bien, como señala Arenal desde su revista, porque obliga a que pasen dos horas diarias bajo la lluvia y el frío ( $L a$ Voz de la Caridad, 15- I-1872).

Vuelve a insistir en la necesidad del culto, esta vez en el ejército, de manera que las ambulancias lleven un capellán, y también en las prisiones porque considera que, especialmente a las de mujeres les sirve de consuelo (La Voz de la Caridad, 1-IX-1873).

\section{LOS DESAHUCIOS Y LA FALTA DE VIVIENDAS SOCIALES}

En 1871, Arenal publica su artículo "El cochero que merecía andar dentro del coche" (La Voz de la Caridad, 15-III-1871), donde plantea en forma de noticia un tema de plena actualidad como el del desalojo de las viviendas. En su caso, la protagonista ha sido una anciana desvalida en la calle de la Reina que no ha podido pagar su alquiler y a la que acaba socorriendo un cochero que habita en la buhardilla vecina: "Las prevenciones de clase son siempre injustas; el pensar así desfavorablemente es malo y hace mal", concluye Arenal.

La situación de la vivienda en la capital, con una afluencia de personas que llegaban del campo para tratar de incorporarse a la industria, era crítica por su escasez y carestía.La idea de crear una sociedad de caridad para construir viviendas para obreros, $L a$ Constructora Benéfica, surgió a raíz de un donativo hecho el año 1872 por la condesa Krasinski en París, al embajador entonces en la capital francesa, Salustiano de Olózaga. A la cantidad inicial se añadió la aportada en su testamento por Gertrudis Gómez de Avellaneda y el producto de la suscripción abierta en Paris, todo lo cual ascendía, ya en el mes de mayo de 1875 , a 200.000 reales, aproximadamente. Ese año, el alcalde, conde de Toreno, reúne a personalidades de ideología distinta y a varios diarios para llevar a cabo la idea y elaborar los estatutos ( $L a$ Voz de la Caridad, 15-VI-1875).

Arenal reconoce que muchas personas no están de acuerdo con un barrio exclusivo para obreros, que quedarían aislados, y lo comprende: "pero la hostilidad entre las clases es más profunda aislando la vivienda que separando el corazón". Argumenta que hay muchos más pobres que ricos, que el valor de las casas de estos es prohibitivo para ellos, entre otras cosas porque cuando se derriba una vivienda humilde se construye otra mejor lo que obliga a varias familias pobres a vivir apiñadas de alquiler. En los grandes barrios que se han hecho entonces para ricos, Salamanca y Argüelles, no hay habitaciones para ellos; había algunas en el de Pozas en condiciones higiénicas y económicas que no eran deseables.

Defiende nuestra autora la separación por clase económica para evitar que en un portal lujoso coincidiera el que habitaba en una miserable "boardilla" e iba descalzo con el vecino que tenía un lujoso gabinete (La Voz de la Caridad, 15-V-1876).

Las viviendas que se proyectaban, modestas pero higiénicas, permitirían que pagando unas cuotas mensuales pudieran llegar a ser propietarios al cabo de unos años. Compraron unos terrenos en el barrio de Pacífico, a ambos lados de la calle de la Caridad, esquina a la Ciudad de Barcelona. Años después esta Asociación construiría viviendas en la calle de su nombre 
y Tenerife, en Cuatro Caminos y en 1876 unas casitas unifamiliares en el barrio de Tetuán, diseñadas por el arquitecto Arturo Calvo Tomelén.

3.1. La repatriación. Hemos visto cómo en el último tercio del siglo XIX Ilegan a la capital gentes del extranjero y de otras provincias tras pasar un auténtico calvario en el camino en muchos casos. En su trabajo "Al pueblo de su naturaleza", Arenal explica que cuando se les reenvía a su pueblo de origen de manera forzada, ya sean débiles o fuertes, peligrosos o inofensivos se encuentran sin nada que hacer y repiten lo que hacían en la ciudad: los trabajadores intentar buscar trabajo y los holgazanes vagar, y todos acaban pidiendo para comer casi sin excepción

Los pueblos pequeños carecían de medios y si en la capital no existía "trabajo para los útiles, caridad para los impedidos y cárcel para los delincuentes", los alcaldes de los pueblos eran aún más impotentes para ocuparse de ellos y, por lo general, los vecinos trataban de proteger a los mendigos frente a los agentes de la autoridad.

...Esta debía meditar sobre el hecho; considerar si la conciencia pública está extraviada o el funcionario se extralimita, y preguntarse por qué se aplaude a la policía cuando reduce a prisión a un delincuente, y se la censura cuando lleva preso a un mendigo (La Voz de la Caridad, 1-V-1880 y 1-VI1880).

Diferencia entre el mendigo y el que pide limosna. Mendigo es el que vive de implorar constante y públicamente la caridad y los hay de dos clases: unos que no pueden trabajar, y otros que no quieren.

\section{EL ALCOHOLISMO}

Entre los muchos retratos de los problemas sociales que la rodean, Arenal va a detenerse en uno de los más generales entre las clases humildes, el de la embriaguez, que para ella tiene todos los caracteres esenciales del delito y habría que penarlo, porque ataca a la moral y produce una honda perturbación social. Como cree que el pobre empieza a beber por distracción, divide las diversiones en juegos y tertulias que deberían ser honestas e instructivas ( La Voz de la Caridad, 1-II-1874).

Reconoce que la opinión pública es permisiva y no lo considera punible, ella cree que es un vicio de gente ordinaria; una rareza en las personas decentes; en suma, la embriaguez no es un delito ni una deshonra, y el gobierno que recorta derechos civiles o políticos no le niega a ningún español el de embriagarse. Opina que el español es "naturalmente sobrio", de manera que si la ley y la opinión pública condenasen la embriaguez pronto disminuiría. Tres años después reconoce que no basta con considerarla un delito porque es preciso a la vez condenar a la taberna que lo permite con un aumento de la contribución: "Los crímenes y los vicios de los pobres salen casi todos de sus pasatiempos, que nadie procura que sean racionales, honestos y hasta instructivos, como podían ser" (La Voz de la Caridad, 15-II-1876)

En su artículo "Vicio, delito y crimen" explica que en Inglaterra se considera a la dipsomanía como locura, algo con lo que no está conforme y se mantiene en su idea de delito y pide que se la persiga directa o indirectamente, aunque con cierta blandura, en consideración a la dificultad de la enmienda tras muchos años de culpa e insiste de nuevo en la necesidad de diversiones racionales (La Voz de la Caridad, 1-IV-1876).

\section{EL SUELDO DE LOS OBREROS}

Resulta interesante la opinión de Arenal, propietaria y madre de un ingeniero de los de entonces, sobre las retribuciones convenientes a los obreros por su trabajo. En el artículo "¿El alto salario es el bienestar del obrero?" (La Voz de la Caridad, 15-XII-1876) se muestra convencida de que un salario alto y seguro conduce al derroche y toma como ejemplo la situación de la fábrica de cristales de Gijón, donde los operarios no son ricos pero hacen su capitalito, lo mandan a su país si son extranjeros, se dedican a los negocios o se dan a la buena vida y lo gastan en comer y beber. La pobreza, también moral e intelectual que les supone no se remedia solo con un sueldo alto y destaca su diferente reacción frente a las clases bien acomodadas, que si no hacen economías, gastan en cultivar su espíritu o en proporcionarle goces con los libros, la música, teatro, etc. La inexistencia de equilibrio entre los medios materiales y los intelectuales en la gente llamada "baja" con altos salarios es un peligro porque carecen de freno, aunque comprende que pidan aumento de salario.

\section{LA CAJA DE AHORROS DE MADRID}

Las Cajas de Ahorro se fundaron en España en el siglo XVIII, y la de Madrid en 1702 por Francisco Piquer, con una finalidad benéfica. Arenal va a cuestionar su gestión y algunas de sus decisiones en 1879 y explica así el funcionamiento:

...el Monte de Piedad y Caja de Ahorros dice al público: Si quieres traerme tus economías, las presta- 
ré al 7 por 100, aproximadamente, y te daré el cuatro; ya que el rédito sea tan mezquino, tan poco a propósito para estimularte al ahorro, al menos tendrás seguridad (La Voz de la Caridad, 15-V-1879).

La entidad respondía de los fondos que se le confiaban formando reglamentos, exigiendo formalidades, tomando precauciones y nombrando empleados. La realización de sus fines es lo que ya entonces Arenal ponía en duda: "mi fianza material es un capital cuantioso, mi fianza moral es mi crédito, mi justicia la respetabilidad de las personas que dirigen mis asuntos" (La Voz de la Caridad, 15-V-1879).

En su caso, la falta de confianza ha surgido tras un incidente donde la estafada ha sido la propia Caja y no el imponente, de manera que aunque su empleado resulte culpable, la entidad tiene que pagar la cantidad estafada, porque el público no confía el dinero a un empleado sino a la Caja.

Para vencer el obstáculo de la falta de fondos, las Cajas solían unirse a los Montes de Piedad, de modo que con las economías del impositor hacían el anticipo al que necesitaba un préstamo. La combinación era beneficiosa en opinión de Arenal, siempre que la diferencia fuera escasa entre lo que ofrece de interés y lo que pide por el préstamo. Cuando esta era muy grande, como sucedía en la Caja de Ahorros y Monte de Piedad de Madrid, no animaba a confiar los ahorros por la escasez de interés que ofrecía: "Es deplorable, por muchos conceptos, que las economías del pobre no hallen empleo más beneficioso, o que cuando tiene que pedir prestado se le exija tanto interés".

Concluye con una crítica al gasto superfluo que acaba de realizar el Monte de Piedad de Madrid con el nuevo edificio, en un solar que ha costado un gran capital, en el centro de la capital, que no era el lugar donde estaban los pobres, con lujo arquitectónico en la decoración de los salones y las elegantes habitaciones de los empleados:

...las pretensiones de servir la estética dan por resultado la deformidad moral de hacer gastos innecesarios a costa de los necesitados, a quienes no producirá buen efecto el lujo que allí ven, y precisamente en un momento en que el contraste con su situación debe dar lugar a reflexiones que no redundan en elogio del establecimiento, y que probablemente haría el fundador si viviera ( $L a$ Voz de la Caridad, 15-III- 1880).

Censura el que la epidemia del lujo haya afectado incluso a lugares donde no debía existir y que, como contraste con los excesivos intereses que pide por los préstamos, tenga un horario muy corto de apertura y no acepte muchos objetos, lo que llevaba a muchos al usurero.

\section{LA FIESTA DE LOS TOROS}

La carta enviada por un lector a Arenal manifestando su perplejidad por la reacción negativa de su esposa e hija, a las que había invitado a una corrida de toros, va a permitir a nuestra autora exponer, sin ninguna clase de diplomacia, su opinión sobre la fiesta. Achaca a la rutina y falta de razonamiento en una persona culta el no considerar la acción en sí, sin tener en cuenta los elogios o ataques de que es objeto. Duda de que la mayoría de los españoles sea favorable a un espectáculo sangriento y, en cualquier caso, cree que hay que guiarse no por el juicio de los más, sino de los mejores. Él ha seguido el ejemplo de su padre y del vulgo moral, al que considera aunque vaya bien vestido y en coche.

Reconoce el atractivo poderoso de la lucha para los hombres, y su poder para embotar la sensibilidad de las masas. En las corridas, los espectadores se acostumbran a los horrores y multiplican sus instintos crueles por lo que es necesario que la sociedad contenga las malas inclinaciones humanas y fomente las buenas, que son justo las contrarias a esa lucha sangrienta que además está presidida por la autoridad y protegida por la ley.

Se convierte al toro, que es un animal manso y útil, en una fiera que trata de huir y que ataca cuando le obligan en una reacción natural en legítima defensa frente al agresor, por lo que Arenal considera grave el que el más razonable en la Plaza de Toros sea el toro.

Además de la inmoralidad que supone torturar a un animal inocente, cree que no hay razón alguna para que un hombre arriesgue su vida por dinero y para diversión de otros, aunque puede alegar como atenuante el que es un hombres sin instrucción, pobre y al que tienta el poder convertirse en rico, ser admirado e invitado por los grandes que le regalan joyas y le invitan a su mesa.

Reconoce que los espectadores no son los pobres, que no pueden pagar la entrada sino la gente "distinguida", la aristocracia y la clase culta se ponen al nivel de la plebe más ignorante con su lenguaje, maneras groseras y dureza, todos se convierten en chusma El peor es el presidente, que como funcionario público autoriza todo aquel sangriento espectáculo que, en lugar de buscar el bien, coopera al mal: 
¿No quieren todos que haya muchos caballos muertos, muchas tripas colgando, mucha horrible tortura de aquellos nobles y útiles animales, servidores del hombre, que, en pago de que le auxiliaron toda la vida, les da por diversión una horrible muerte? ¿No llaman todos bueno al toro que hace más daño, mejor cuantos más dolores causa y pone en mayor peligro la vida de los lidiadores? (La Voz de la Caridad, 1-VI-1877).

Todos cooperan al enriquecimiento de los empresarios, "traficantes de dolores y sangre" y del torero que gana en tres horas lo que un trabajador en un año. Le sorprende que se entusiasmen por la habilidad del diestro y no lo hagan ante una obra de arte o un descubrimiento científico, de la misma manera que tras ser herido de muerte un lidiador continúen divirtiéndose en la plaza.

Su conclusión es que en la Plaza el público es la fiera y le sorprende el cartel en que se le dice: "que en caso de inutilizarse los cinco picadores no tiene derecho a pedir que salgan más" (La Voz de la Caridad, 1-VI1877).

Queda palpable cómo aún perviven en España muchos de los problemas planteados ya en el siglo XIX por esta mujer excepcional, que tuvo la valentía de defender sus ideas frente al poder establecido, aunque en ocasiones este estuviera en manos amigas.

\section{APÉNDICE}

Concepción Arenal. Trabajos en prensa citados

La Iberia, Madrid, 1855

El Cristianismo, Madrid, 1862

El Álbum de las Familias, Madrid, 1866

El Moro Muza, La Habana, 1869

La Voz de la Caridad, Madrid, 1870-1884

La llustración de Madrid, Madrid, 1871

El Abolicionista, Madrid, 1873, 1875

Revista de España, Madrid, 1875

El Correo de la Moda, Madrid, 1878-9, 1882

La llustración gallega y asturiana, Madrid, 18801881

Boletín de la Institución Libre de Enseñanza, Madrid, $1883,1884,1889-1893$

La llustración Española y Americana, Madrid, 1892

Las Dominicales del Librepensamiento, Madrid, 1892

La España Moderna, Madrid, 1889-1895

\section{NOTAS}

1 Los 23 números anuales formaban un tomo y el precio de la suscripción era de 10 reales al semestre en provincias, 19 rs. en las Antillas españolas y 15 rs. en el extranjero. A los tres años de su existencia, en 1873 , tan solo llegaban al millar. El tomo V, en 1875 , se subtitula ya Revista quincenal de beneficencia y establecimientos penales y órgano oficial de la Sección de Señoras de la Cruz Roja (LVC,15-III-1875). 